\title{
Temperatura e umidade do solo em função do uso de cobertura morta no cultivo de milho
}

\section{Soil temperature and soil moisture depending on the use of mulch in maize cultivation}

\author{
Francielle Freitas VIEIRA ${ }^{1}$; Rivanildo DALLACORT ${ }^{2}$; \\ João Danilo BARBIERI ${ }^{3}$; Flavio Carlos DALCHIAVON ${ }^{4}$; Diego Fernando DANIEL ${ }^{5}$
}

${ }^{1}$ Mestre em Ambiente e Sistemas de Produção Agrícola, Universidade do Estado de Mato Grosso - UNEMAT, MT-358, 7 -
Jardim Aeroporto, Tangará da Serra - MT, 78300-000, e-mail: franciellefreitascosta@hotmail.com
2 Professor Doutor em Agronomia, Universidade do Estado de Mato Grosso - UNEMAT, e-mail: rivanildo@unemat.br
${ }^{3}$ Autor para correspondência. Doutorando em Agronomia, Universidade Estadual de Maringá - UEM, Av. Colombo, 5790 - Jd.
Universitário, Maringá - PR, 87020-900, e-mail: joaodanilobarbieri@hotmail.com
${ }^{4}$ Professor Doutor efetivo do Instituto Federal de Educação, Ciência e Tecnologia de Mato Grosso, Campus Parecis, MT 235,
km 12; s/n, Caixa Postal n. 100, Zona Rural, - Campo Novo do Parecis, MT, 78360000 e-mail:
flavio.dalchiavon@cnp.ifmt.edu.br
${ }^{5}$ Mestrando em Ambiente e Sistemas de Produção Agrícola, Universidade do Estado de Mato Grosso - UNEMAT, e-mail:
diegodanielmt@gmail.com

Recebido em: 10-04-2019; Aceito em: 28-01-2020

\section{Resumo}

Objetivou-se avaliar a influência de diferentes quantidades de cobertura vegetal morta sobre a temperatura e a umidade do solo cultivado com milho, em Tangará da Serra, MT. O experimento foi realizado no ano de 2016, na área experimental da Universidade do Estado de Mato Grosso (UNEMAT). Analisou-se a resposta da temperatura do solo em clima tropical com estação seca no inverno (Aw segundo Köppen), em um Latossolo Vermelho distroférrico na região sudoeste do estado de Mato Grosso. Foram avaliados três tratamentos com duas repetições, sendo: sem cobertura vegetal; cobertura com $4 \mathrm{t} \mathrm{ha}^{-1}$ de massa seca de braquiária e cobertura com $8 \mathrm{tha}^{-1}$ de massa seca de braquiária. A temperatura foi monitorada através de sensores termopar do tipo $\mathrm{K}$, instalados nas profundidades de 5-10 e 20-25 cm e para a umidade utilizou-se sondas de reflectometria no domínio do tempo (TDR), instalados a $30 \mathrm{~cm}$ de profundidade. A temperatura do solo foi reduzida com o uso da palhada de braquiária, principalmente na fase inicial de desenvolvimento da planta. As maiores variações na temperatura ocorreram na profundidade de $5-10 \mathrm{~cm}$. O solo coberto com $8 \mathrm{t} \mathrm{ha}^{-1}$ reduziu a temperatura máxima do solo em até $2,9 \stackrel{\circ}{ } \mathrm{C}$, além disso, a cobertura do solo proporcionou a redução da amplitude térmica no solo de 5,3 e $5,8 \stackrel{\circ}{\circ} \mathrm{C}$, com 4 e $8 \mathrm{t}^{-1}{ }^{-1}$, respectivamente. A umidade do solo foi maior no cultivo de milho com cobertura de $8 \mathrm{t} \mathrm{ha}^{-1}$ de braquiária.

Palavras-chave adicionais: amplitude térmica; reflectometria no domínio do tempo; termopar; Zea mays L.

\begin{abstract}
The objective was to evaluate the influence of different amounts of mulch on the temperature and moisture of soil cultivated with maize, in Tangará da Serra, MT. The experiment was carried out in 2016, in the experimental area of the State University of Mato Grosso (UNEMAT). Soil temperature response was analyzed in a tropical climate with a dry season in winter (Aw according to Köppen), in a dystropheric Red Latosol in the southwestern region of the state of Mato Grosso. Three treatments with two replications were evaluated, being: without vegetation cover; cover with $4 \mathrm{t} \mathrm{ha}^{-1}$ of dry mass of brachiaria and cover with $8 \mathrm{t} \mathrm{ha}^{-1}$ of dry mass of brachiaria. The soil temperature was monitored by type $\mathrm{K}$ thermocouple sensors, installed at depths of 5-10 and $20-25 \mathrm{~cm}$, and for soil moisture, time domain reflectometry probes (TDR), installed at $30 \mathrm{~cm}$ depth, were used. The soil temperature was reduced with the use of brachiaria straw, mainly in the initial stage of plant development. The greatest variations in temperature occurred at a depth of $5-10 \mathrm{~cm}$. The soil covered with $8 \mathrm{t} \mathrm{ha}^{-1}$ reduced the maximum soil temperature by up to $2.9^{\circ} \mathrm{C}$, in addition, the soil cover provided a reduction in the soil thermal amplitude of 5.3 and $5.8^{\circ} \mathrm{C}$, with 4 and $8 \mathrm{t} \mathrm{ha}^{-1}$, respectively. The soil moisture was higher in the cultivation of maize with coverage of $8 \mathrm{tha}^{-1}$ of brachiaria.
\end{abstract}

Additional keywords: temperature range; thermocouple; time domain reflectometry; Zea mays L.

\section{Introdução}

O estado de Mato Grosso, situado na região Centro-Oeste do Brasil é o principal produtor brasileiro de milho, em consequência da sucessão soja-milho desta região. Segundo a CONAB (2020), a produtividade média do milho na safra 2018/2019 no estado de Mato Grosso foi de $6.376 \mathrm{~kg} \mathrm{ha}^{-1} \mathrm{e}$ a produtividade nacional foi de $5.719 \mathrm{~kg} \mathrm{ha}^{-1}$, sendo que a produção no estado atingiu 31,31 milhões de toneladas, nesse 
contexto o Mato Grosso colheu uma das maiores produções já registradas.

O cultivo do milho tem se tornado cada vez mais frequente, principalmente devido à vantagem de obtenção de melhores preços em períodos de entresafra (Garcia et al., 2012). Logo, a adoção de práticas de manejo cultural conservacionistas, constituem importante alternativa para assegurar o uso sustentável do solo nesta região.

Estudos demostram que os sistemas de manejo com utilização de palhada sobre o solo influenciam na temperatura e na umidade do solo (Veiga et al., 2010). Neste sentido, a cobertura vegetal, considerada uma prática conservacionista, proporciona inúmeros benefícios ao solo, dentre os quais podemos citar, a menor ocorrência de plantas daninhas, redução da perda de água do solo, contribuindo para a manutenção da umidade, incrementos na matéria orgânica do solo, que por sua vez beneficia os microrganismos do solo (Carneiro et al., 2008; Souza et al., 2008; Santos et al., 2011).

A cobertura morta existente sobre o solo também contribui para reduzir a temperatura do solo, e isso acontece em função das propriedades térmicas dos materiais utilizados na cobertura, que constituem em uma barreira física, que evitam a incidência direta da radiação solar, reduzindo as oscilações da temperatura do solo (Gasparim et al., 2005). Temperaturas do solo muito elevadas dificultam o processo germinativo das sementes, têm efeito negativo sobre o desenvolvimento das plântulas e raízes e, na atividade microbiana do solo, além de comprometerem a absorção de nutrientes pelas plantas (Furlani et al., 2008; Albuquerque et al., 2013).

Segundo Landau et al. (2012), a temperatura do solo ideal para a cultura do milho situa-se entre $25 \mathrm{e}$ $30^{\circ} \mathrm{C}$, sendo que temperaturas do solo inferiores a $10 \stackrel{\circ}{\mathrm{C}}$ ou superiores a $40 \stackrel{\circ}{\mathrm{C}}$ geram perdas significativas à germinação e, consequentemente, à produtividade de grãos. Além de amenizar estes fatores restritivos à produtividade, a cobertura do solo contribui para a conservação dos atributos do solo, diminuindo a compactação e a desagregação e elevando a porosidade e a capacidade de infiltração do solo (Collier et al., 2011).

O comportamento da umidade e da temperatura do solo influenciam os mais diversos fatores ligados as culturas agrícolas e sua produtividade (Stefanoski et al., 2013), desta maneira o conhecimento de como um solo se comporta quando submetido a utilização de cobertura sobre o mesmo é de grande importância para o entendimento das relações existentes entre solo-planta em regiões de cerrado e podem oferecer subsídios para o estudo de técnicas de cultivo mais adequadas.

Estudos deste tipo oferecem bases para 0 desenvolvimento de técnicas de cultivo mais adequadas, inclusive ecologicamente e economicamente, para os diversos tipos de clima e solo. Desta maneira, além do clima de uma região, o conhecimento de como a temperatura e a umidade variam em diferentes profundidades no solo, principalmente em solos existentes nas principais regiões agrícolas do Brasil, contribui para o aprofundamento do conhecimento do tema investigado (Oliveira et al., 2019).

Devido à importância e a influência que a cobertura morta exerce sobre a temperatura e umidade em solos de cerrado, objetivou-se avaliar o efeito de diferentes quantidades de cobertura vegetal morta sobre a temperatura e a umidade do solo cultivado com milho, em Tangará da Serra, MT.

\section{Material e métodos}

O experimento foi realizado na área experimental da Universidade do Estado de Mato Grosso - UNEMAT, Campus de Tangará da Serra e, nas dependências do Centro de Pesquisas, Estudos e Desenvolvimento Agroambientais - CPEDA, no Laboratório de Agrometeorologia, no ano de 2016.

O clima da região é do tipo Aw, de acordo com a classificação de Köppen (tropical com estação seca no inverno) e o solo é classificado como Latossolo Vermelho distroférrico argiloso (Santos et al., 2018). Os valores médios anuais de temperatura do ar, de precipitação pluviométrica e de umidade relativa do ar são $26,1^{\circ} \mathrm{C}, 1.830 \mathrm{~mm}$ e $70-80 \%$, respectivamente, onde as chuvas são praticamente concentradas de outubro a março e entre abril e setembro estabelece-se a estação seca (Dallacort et al., 2010; Dallacort et al., 2011).

Próximo à área experimental está instalada uma estação meteorológica automática, modelo Campbell Scientific, localizada a $14^{\circ} 65^{\prime} 00^{\prime \prime} \mathrm{S}, 57^{\circ} 43^{\prime}$ $15^{\prime \prime} \mathrm{W}$, com elevação de 440 metros, da qual foram obtidos os dados meteorológicos. Assim, as principais informações meteorológicas consideradas no período da condução do experimento foram temperatura do ar (médias, máximas e mínimas), precipitação pluviométrica, umidade relativa do ar, velocidade do vento e radiação solar global, cujos valores médios mensais estão apresentados na Tabela 1.

O experimento foi realizado em seis lisímetros de pesagem, com área de 2,25 $\mathrm{m}^{2}(1,50 \times 1,50 \mathrm{~m}) \mathrm{e}$ $1,20 \mathrm{~m}$ de profundidade existentes na área experimental (Fenner et al., 2016). Este experimento foi realizado nos lisímetros pois os sensores de temperatura e umidade do solo utilizados já estavam previamente instalados dentro do solo que preenche os lisímetros.

A semeadura do milho foi realizada no dia 26/07/2016, manualmente nos seis lisímetros e, no mesmo dia foi realizada a semeadura de bordadura, pelo método de semeadura direta com uma semeadora modelo Baldan PP-SOLO-4500, totalizando $500 \mathrm{~m}^{2}$ de bordadura entorno dos lisímetros. O espaçamento utilizado foi de 0,45 m entre fileiras, sendo a cultivar utilizada a AG 7088 RR, híbrido simples, de ciclo precoce, com população de 60.000 plantas por hectare. 
A adubação foi realizada de acordo com análise química do solo (Tabela 2). As características físicas do solo para os lisímetros e para área de bordadura foram: areia $\left(256 \mathrm{~g} \mathrm{~kg}^{-1}\right)$, silte $\left(156 \mathrm{~g} \mathrm{~kg}^{-1}\right)$ e argila $\left(588 \mathrm{~g} \mathrm{~kg}^{-1}\right)$ e para a área ao entorno dos lisímetros (bordadura): areia $\left(290 \mathrm{~g} \mathrm{~kg}^{-1}\right)$, silte $\left(166 \mathrm{~g} \mathrm{~kg}^{-1}\right)$ e argila $\left(544 \mathrm{~g} \mathrm{~kg}^{-1}\right)$.

Conforme o resultado da análise, foi realizada a calagem do solo, elevando a saturação por bases (V) até $60 \%$, levando em consideração a condição irrigada e tipo de solo existente na região. A adubação de base constituiu de $45 \mathrm{~kg} \mathrm{ha}^{-1}$ de $\mathrm{K}_{2} \mathrm{O}$ e $95 \mathrm{~kg} \mathrm{ha}^{-1}$ de $\mathrm{P}_{2} \mathrm{O}_{5}$, aplicados na linha da semeadura. No total, aplicou-se $314 \mathrm{~kg} \mathrm{ha}^{-1}$ de N parcelados em três aplicações, sendo uma na semeadura e duas aplicações em cobertura: a primeira quando a cultura estava no estádio V4 (13 dias após a emergência - DAE) e a segunda no estádio V8 (27 DAE) de desenvolvimento.

Tabela 1 - Dados meteorológicos obtidos e de irrigação durante o período do experimento, da semeadura até a colheita do milho. Tangará da Serra - MT, 2016. Meteorological data during the experiment period from sowing to harvesting of maize crop. Tangará da Serra - MT, 2016.

\begin{tabular}{lcccccc}
\hline \multicolumn{1}{c}{ Meses } & $\begin{array}{c}\text { Prec. } \\
(\mathrm{mm})\end{array}$ & $\begin{array}{c}\text { Irrig. } \\
(\mathrm{mm})\end{array}$ & $\begin{array}{c}\text { UR média } \\
(\%)\end{array}$ & $\begin{array}{c}\text { T. média } \\
\left({ }^{\circ} \mathrm{C}\right)\end{array}$ & $\begin{array}{c}\text { Vento } \\
\left(\mathrm{m} \mathrm{s}^{-1}\right)\end{array}$ & $\begin{array}{c}\text { Rad. } \\
\left(\mathrm{MJ} \mathrm{m}^{-2}\right)\end{array}$ \\
\hline Julho & 0,00 & 185,44 & 31,09 & 23,97 & 2,67 & 7,11 \\
Agosto & 61,71 & 263,58 & 34,75 & 25,16 & 3,00 & 6,63 \\
Setembro & 31,74 & 146,46 & 50,09 & 23,80 & 2,78 & 12,31 \\
Outubro & 78,90 & 0,00 & 45,87 & 25,94 & 2,71 & 19,27 \\
Novembro & 89,66 & 0,00 & 58,43 & 24,95 & 2,70 & 16,38 \\
\hline Média & - & - & 43,89 & 24,87 & 2,80 & 12,57 \\
\hline
\end{tabular}

Prec = Precipitação; Irrig = Irrigação; UR média = Umidade relativa média do ar; T. média = Temperatura média do ar; Vento = Velocidade média do vento; Rad = Radiação solar global. Prec = Precipitation; Irrig = Irrigation; UR média = Average relative air humidity; . média = Average air temperature; Vento = Wind speed; Rad. = Global solar radiation .

Tabela 2 - Características químicas do solo* na profundidade de $0-20 \mathrm{~cm}$ da área experimental da Universidade do Estado de Mato Grosso (UNEMAT), em Tangará da Serra - MT. Soil chemical characteristics ${ }^{\star}$ at depth of $0-20 \mathrm{~cm}$ from the experimental area of the State University of Mato Grosso (UNEMAT), in Tangará da Serra - MT.

\begin{tabular}{|c|c|c|c|c|c|c|c|c|c|c|c|c|}
\hline \multirow{2}{*}{$\begin{array}{c}\text { Amostra } \\
(\mathrm{cm})\end{array}$} & \multicolumn{2}{|c|}{$\mathrm{pH}$} & & K & $P \perp M a$ & Ca & $\mathrm{Mg}$ & Al & $\cdots$ & $\mathrm{CIC}$ & \multirow{2}{*}{$\begin{array}{l}\mathrm{V} \\
(\%)\end{array}$} & \multirow{2}{*}{$\begin{array}{c}\text { M.O. } \\
\left(\mathrm{g} \mathrm{dm}^{-3}\right)\end{array}$} \\
\hline & $\mathrm{H}_{2} \mathrm{O}$ & $\mathrm{CaCl}_{2}$ & & $\left.n^{-3}\right)$ & & $\cdots$ & (cmc & $\mathrm{dm}^{-}$ & & & & \\
\hline $0-20$ & 5,30 & 4,50 & 70 & 7,20 & 1,75 & 1,25 & 0,50 & 0,35 & & 6,72 & 29,02 & 28,70 \\
\hline
\end{tabular}

*AGROANÁLISE - Laboratórios Integrados, Cuiabá - MT. (Maio - May/2016).

O experimento foi composto por três tratamentos e 2 repetições, com área útil de 2,25 $\mathrm{m}^{2}$ $(1,50 \mathrm{~m} \times 1,50 \mathrm{~m})$ cada repetição, ou seja, os tratamentos foram inseridos dentro dos lisímetros, sendo que cada 2 lisímetros recebia um tratamento. A área total das parcelas foi de $13,5 \mathrm{~m}^{2}$ (área dos 6 lisímetros) e com a área de bordadura a área total do experimento foi de $513,5 \mathrm{~m}^{2}$ (Figura 1 ).

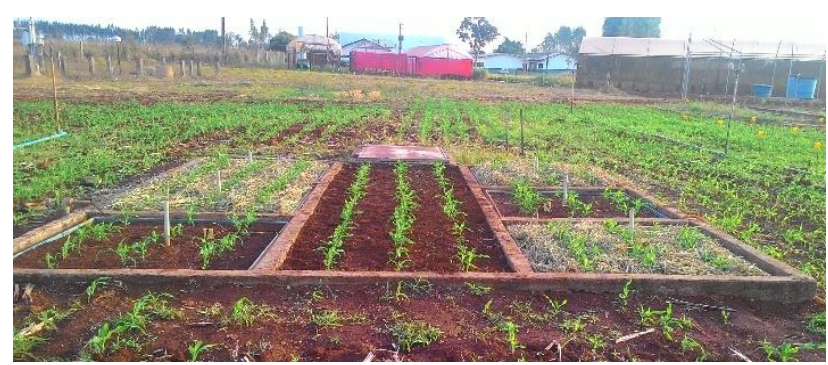

Figura 1 - Disposição dos tratamentos dentro dos lisímetros. Arrangement of treatments within lysimeters.

Os sensores de temperatura e umidade utilizados estavam inseridos no solo dentro dos lisímetros. Os tratamentos foram constituídos por diferentes níveis de cobertura de solo cultivado com milho, sendo: T1: cultivo de milho sem cobertura de palhada sobre o solo; T2: cultivo de milho com $4 \mathrm{t} \mathrm{ha}^{-1}$ de cobertura de palhada de braquiária sobre o solo; T3: cultivo de milho de milho com $8 \mathrm{t} \mathrm{ha}^{-1}$ de cobertura de palhada de braquiária sobre o solo. Os níveis de cobertura de solo foram decididos com base nos requisitos importantes para o sucesso do plantio direto, dispondo em torno de $6 \mathrm{t} \mathrm{ha-1}$ de matéria seca inicial para cobertura do solo, com base nisso foi estudado a temperatura e umidade do solo sem cobertura e com 4 e $8 \mathrm{t} \mathrm{ha}^{-1}$ de matéria seca (Cruz et al., 2006; Murga-Orrillo et al., 2016).

A palhada para compor os níveis de cobertura do solo foi proveniente da Brachiaria brizantha, que foi coletada nas dependências da própria UNEMAT próximo ao experimento, cultivada periodicamente em um campo agrostológico pertencente à Universidade. A disposição da palhada nos tratamentos ocorreu aos 14 dias após semeadura. A determinação da quantidade 
de massa seca de palhada se deu por meio da coleta de 4 amostras do volume total de palhada (Massa úmida), sendo realizado a secagem em estufa de circulação forçada de ar, com temperatura de aproximadamente $65^{\circ} \mathrm{C}$, durante 72 horas ou até atingirem massa constante (Massa Seca), posteriormente determinou-se a porcentagem de massa seca do material e calculou-se a quantidade de material necessário para cada tratamento, para as quantidades utilizadas em toneladas por hectare nesse experimento.

Foram determinadas fases fenológicas com base no crescimento e desenvolvimento da cultura do milho de acordo com o boletim FAO - 56 (Allen et al., 1998), para a determinação da temperatura e da umidade do solo nos diferentes estádios de desenvolvimento, sendo: I) fase inicial: da semeadura até $80 \%$ da de cobertura do solo pelas plantas; II) fase intermediária: de $80 \%$ da cobertura do solo até o início da maturidade fisiológica; III) fase final: início da maturidade fisiológica até à colheita. $\mathrm{O}$ número de dias para cada fase foi decidido por meio de observações em campo e acompanhamento do crescimento da cultura.

A lâmina de irrigação foi determinada por meio do cálculo da evapotranspiração de referência - ETo, com a metodologia de Penman-Monteith FAO-56, com a equação proposta por Allen et al. (1998), com dados obtidos pela estação meteorológica, calculando dessa forma a evapotranspiração da cultura (ETc) que foi determinada pela multiplicação da ETo pelo coeficiente da cultura $(\mathrm{Kc})$ nas diferentes fases das plantas, segundo o boletim 56 da FAO (Allen et al., 2006), e dividido pela eficiência do sistema de irrigação, para a determinação da disponibilidade total de água no solo, lâmina líquida, turno de rega e tempo de irrigação segundo metodologia descrita em Freitas et al. (2018).

A irrigação foi realizada sempre depois das 18:00 horas a ponto de atingir a capacidade de campo, realizada sempre que o solo chegasse à proximidade do ponto do murcha permanente. O solo da região em estudo possui umidade na capacidade de campo e ponto de murcha permanente, nos valores de 0,361 e 0,232 $\mathrm{m}^{3} \mathrm{~m}^{-3}$, respectivamente (Daniel, 2011; Silva, 2016).

A irrigação foi realizada por um sistema de irrigação por aspersão composto por aspersores (Eco 232 Frabrimar) com bocais de 4,0 x 2,8 mm espaçados em $12 \times 12$ m, com Coeficiente de Uniformidade de Christiansen de $86 \%$, sob pressão de $30 \mathrm{~m}$ c.a., proporcionando uma lâmina de água aplicada de $9,76 \mathrm{~mm} \mathrm{~h}^{-1}$.

Após a semeadura foi realizada a elevação da umidade do solo para a capacidade de campo, após o que passaram a ser monitoradas a temperatura e a umidade do solo para as condições existentes nos tratamentos estudados.

Os sensores utilizados para medir a temperatura do solo foram os termopares do tipo $\mathrm{K}$, constituídos por cobre e alumínio, unidos em uma extremidade, envoltos por uma cápsula de alumínio e vedados com resina e fita de autofusão, para protegê-los contra a oxidação. O termopar do tipo $\mathrm{K}$ estão disponíveis em variadas sondas (cases), cobrindo temperaturas entre -200 e $1370 \stackrel{\circ}{ } \mathrm{C}$, tendo sensibilidade de aproximadamente $41 \mu \mathrm{V}{ }^{\circ} \mathrm{C}^{-1}$ (Melo, 2013). Na área central de cada tratamento, foram instalados dois sensores verticalmente, sendo um na camada entre 5-10 cm de profundidade do solo e outro a uma faixa de 20-25 cm de profundidade. Os valores de temperatura do solo foram expressos em ${ }^{\circ} \mathrm{C}$.

Para monitorar a umidade do solo, foram utilizadas sondas de reflectometria no domínio do tempo (TDR), do tipo CS-616 (Campbell Scientific Inc., EUA), instaladas no perfil do solo com profundidade entre 0 e $30 \mathrm{~cm}$, na vertical, no centro de cada tratamento, uma vez que as hastes da sonda medem $30 \mathrm{~cm}$, realizando uma média de umidade do solo da camada de 0 a $30 \mathrm{~cm}$ de profundidade, com precisão de $\pm 0,01 \mathrm{~m}^{3} \mathrm{~m}^{-3}$ (Campbell Scientific, 2004; Freitas et al., 2018).

Os valores de umidade do solo obtidos pelas sondas TDR foram ajustados pela equação proposta por Vasconcelos et al. (2018), que realizou calibração dos sensores para o tipo de solo existente no local de estudo. Os dados de umidade do solo foram expressos em umidade volumétrica $\left(\mathrm{m}^{3} \mathrm{~m}^{-3}\right)$.

Tanto os sensores de temperatura quanto os de umidade do solo foram instalados 14 dias após a emergência da cultura do milho. Ambos foram conectados a uma placa multiplexadora, conectados a um Datalogger (CR1000, Campbell Scientific Inc., EUA), programado para armazenar os dados coletados em intervalos de 5 minutos, armazenando a média dos valores a cada hora. Esses dados foram obtidos entre 09 de agosto e 13 de novembro de 2016, (15 a 110 dias após a emergência das plantas - DAE) foram separados em planilhas do Software Exce ${ }^{\circledR}$ e analisados os valores diários das temperaturas média, máxima e mínima, da amplitude térmica e da umidade média do solo, para cada tratamento.

\section{Resultados e discussão}

Durante o período de estudo, a temperatura média do ar foi de $24,9 \stackrel{\circ}{\circ}$. Na profundidade de $5-10 \mathrm{~cm}$ e de $20-25 \mathrm{~cm}$, a temperatura do solo foi maior no tratamento com o cultivo de milho em solo sem cobertura, principalmente na fase inicial, até os $50 \mathrm{DAE}$ (Figura 2).

Foi observada correlação positiva da temperatura do solo com e sem cobertura e a temperatura do ar. Ainda, foi observado que conforme acontece a elevação da temperatura do ar, aumenta também a temperatura do solo na mesma proporção, de modo que essa relação vai reduzindo gradativamente de acordo com a profundidade avaliada, comportamento este observado também por Belan et al. (2013). 


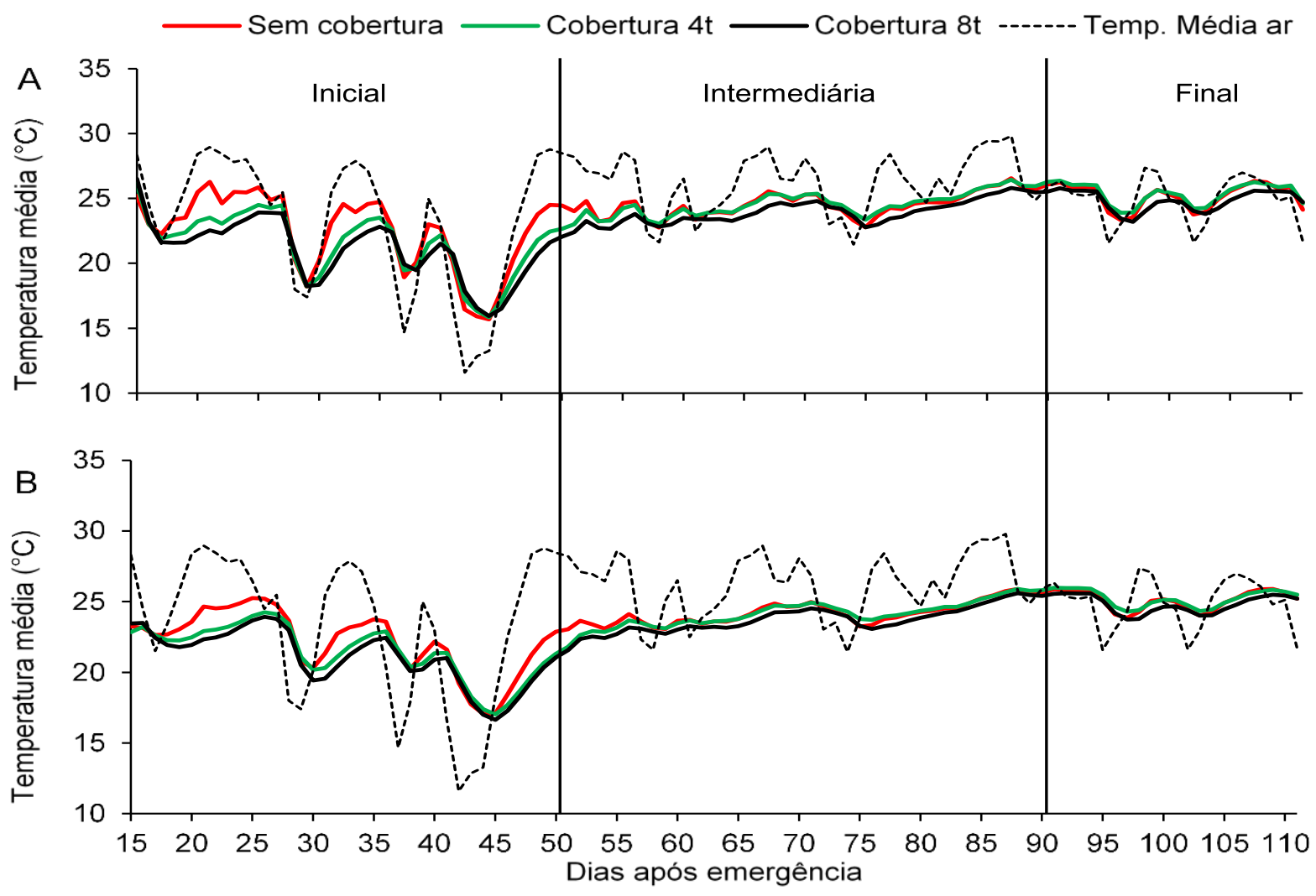

Figura 2 - Temperatura média diária do ar e do solo nos diferentes tratamentos e nas profundidades de 5-10 cm (A) e 20-25 cm (B), avaliadas durante o período de 09 de agosto a 13 de novembro de 2016 (15 a 110 dias após a emergência da cultura do milho). Tangará da Serra - MT. Average daily air and soil temperature in the different treatments and depths of $5-10 \mathrm{~cm}(A)$ and $20-25 \mathrm{~cm}(B)$, evaluated during the period from August 9 to November 13, 2016 (from 15 to 119 days after emergence of the maize crop). Tangará da Serra - MT.

Nas duas profundidades avaliadas, as médias de temperatura do solo permaneceram inferiores à temperatura média do ar, em praticamente todo o período estudado. Nos estádios iniciais da cultura do milho, os valores de temperatura média do solo foram elevados e com grandes variações, isso porque neste período o índice de área foliar é baixo, logo o solo recebia mais energia solar direta (Figura 2).

Aos 50 dias após a emergência até o final das avaliações, houve redução da variabilidade da temperatura do solo entre os tratamentos, com inversão da variação da temperatura média em alguns dias de avaliação, onde o solo cultivado com milho sob com cobertura de $4 \mathrm{t} \mathrm{ha}^{-1}$ de braquiária apresentou valores superiores de temperatura do solo em relação ao cultivado com milho sem cobertura do mesmo, para as duas profundidades avaliadas (Figura 2).

Na profundidade de $5-10 \mathrm{~cm}$ a temperatura do solo foi maior em todos tratamentos, e com maiores variações quando comparadas à temperatura ocorrida aos $20-25 \mathrm{~cm}$ no perfil do solo (Figura $2 \mathrm{~A}$ ). $\mathrm{O}$ tratamento com milho cultivado em solo sem cobertura, na profundidade de $5-10 \mathrm{~cm}$, apresentou variação de 15,7 a $26,5^{\circ} \mathrm{C}$, com média de $23,9{ }^{\circ} \mathrm{C}$. O tratamento com cobertura de $4 \mathrm{t} \mathrm{ha}^{-1}$ de braquiária, apresentou oscilação entre 15,8 e $26,4{ }^{\circ} \mathrm{C}$, com valor médio de
$23,6{ }^{\circ} \mathrm{C}$, e no cultivo com cobertura de $8 \mathrm{t} \mathrm{ha}^{-1}$, as variações ocorreram entre 15,9 a $26,5^{\circ} \mathrm{C}$, com média de 23,1 ${ }^{\circ} \mathrm{C}$ (Figura 2A). Conforme Silva et al. (2006), a cobertura morta mantém estável a temperatura do solo, reduzindo as perdas de água, já que a cobertura protege a superfície do solo dos raios solares.

Em superfícies cobertas com vegetação, o maior aquecimento do solo está relacionado com o seu coeficiente de reflexão da radiação solar (albedo), de maneira que o albedo varia de acordo com tipo de vegetação existente e com o estágio de desenvolvimento em que ela se encotra (Cortez et al., 2015). Wazilewski et al. (2011), verificaram que a utilização de resíduos de cobertura do solo diminui o aquecimento do mesmo, devido à palhada funcionar como um isolante térmico.

Nos tratamentos estudados, aos $5-10 \mathrm{~cm}$ de profundidade, a cobertura influenciou na variabilidade da temperatura do solo. No tratamento com o solo sem cobertura houve maior variação do valor médio, principalmente nos primeiros 40 dias de avaliação (Figura 2A). Em estudo realizado por Dalmago et al. (2004), os autores verificaram maior aquecimento do solo nas primeiras camadas, essencialmente, nos primeiros 30 dias após a emergência das plântulas de 
milho, corroborando os dados deste estudo em que pode-se observar as maiores temperaturas médias no tratamento com solo descoberto.

Na profundidade de $20-25 \mathrm{~cm}$ as oscilações e os valores da temperatura média diminuíram. Para o solo sem cobertura, as variações ocorreram entre 17,1 e $25,9 \stackrel{\circ}{\circ} \mathrm{C}$ e média de $23,6{ }^{\circ} \mathrm{C}$. Com cobertura de $4 \mathrm{t} \mathrm{ha}^{-1}$ de braquiária a temperatura média oscilou de 17,0 a $26,0 \stackrel{\circ}{ } \mathrm{C}$ com média geral de $23,4 \stackrel{\circ}{\circ}$, enquanto no tratamento com $8 \mathrm{t} \mathrm{ha}^{-1}$ de cobertura os valores variaram de 16,6 a $25,6 \stackrel{\circ}{\circ}$, com valor médio de
$22,9 \stackrel{\circ}{\circ}$ (Figura 2B).

Para a temperatura máxima do solo, observou-se maiores variações em ambas as profundidades avaliadas. As diferenças dos valores de temperatura máxima entre os tratamentos com cobertura morta do solo (4 e $8 \mathrm{t} \mathrm{ha}^{-1}$ de braquiária) e sem cobertura são maiores entre eles em relação a temperatura média, principalmente na camada de $5-10 \mathrm{~cm}$ de profundidade, evidenciando a influência da cobertura na variação da temperatura do solo (Figura 3).

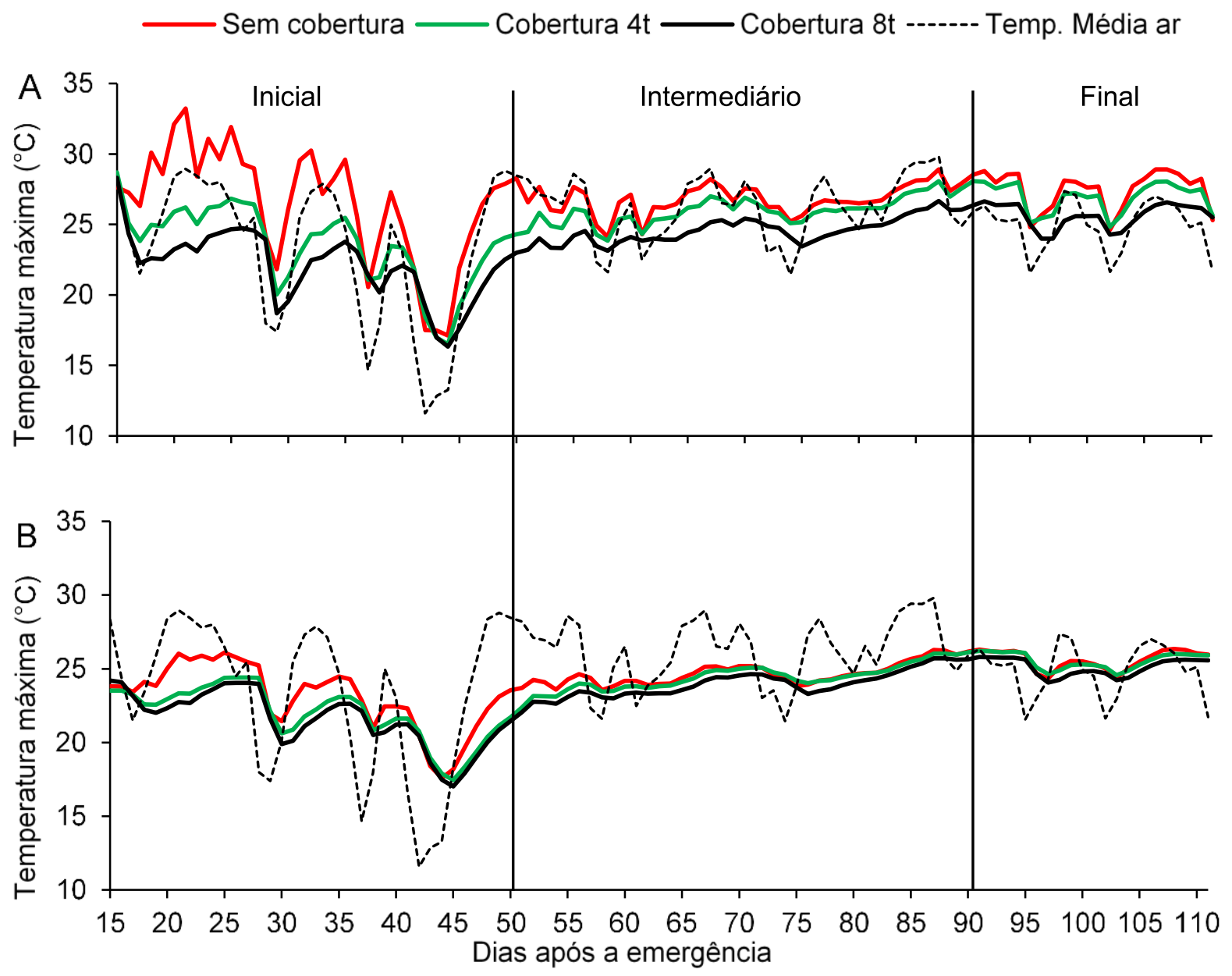

Figura 3 - Temperatura máxima diária do solo nos diferentes tratamentos e nas profundidades de $5-10 \mathrm{~cm}$ (A) e 20-25 cm (B), avaliadas durante o período de 09 de agosto a 13 de novembro de 2016, (15 a 110 dias após a emergência da cultura do milho). Tangará da Serra - MT. Maximum daily soil temperature in the different treatments and depths of $5-10 \mathrm{~cm}(A)$ and $20-25 \mathrm{~cm}(B)$, evaluated during the period from August 9 to November 13, 2016 (from 15 to 110 days after emergence of the maize crop). Tangará da Serra - MT.

Nos $5-10 \mathrm{~cm}$ de profundidade, a temperatura máxima do solo no tratamento sem cobertura, variou de 17,1 a $33,2 \stackrel{\circ}{\circ}$, com valor médio de $26,8 \stackrel{\circ}{ }$. Com cobertura de $4 \mathrm{t} \mathrm{ha}^{-1}$, as variações ocorreram entre 16,5 a $28,7 \stackrel{\circ}{\circ}$, com valor médio de $25,3 \stackrel{\circ}{\circ}$ e com $8 \mathrm{t} \mathrm{ha}^{-1}$ os resultados variaram de 16,3 a $28,3 \stackrel{\circ}{\circ} \mathrm{C}, \mathrm{com}$ média de $23,9 \stackrel{\circ}{\circ}$. Tais dados evidenciaram a importância da cobertura do solo na redução das oscilações da temperatura, demostrando que a cobertura atuou como isolante térmico, reduzindo a temperatura máxima do solo em até $2,9 \stackrel{\circ}{\circ} \mathrm{C}$, com cobertura de 8 t ha $^{-1}$ (Figura 3A). A utilização da cobertura morta sobre o solo reduz a perda de água do solo, mantendo a temperatura estável, fato este, resultante da proteção que a cobertura do solo exerce sobre a superfície do solo, protegendo contra a incidência 
direta dos raios solares e da chuva (Alvarenga et al., 2001).

De acordo com Carneiro et al. (2014), no início do ciclo da cultura quando a cobertura vegetal é baixa, nas camadas superficial do solo $(5$ a $10 \mathrm{~cm}$ de profundidade), o menor albedo do solo com relação ao da vegetação e a incidência de radiação, estabelece que essa camada seque com maior rapidez, por esse motivo, alcance temperaturas máximas superiores à do ar no decorrer do dia (Figura 3A).

Avaliando a temperatura do solo sem cobertura e com cobertura de 4 e $8 \mathrm{t} \mathrm{ha}^{-1}$ de palhada de aveia, Gasparim et al. (2005) também observaram redução da temperatura do solo (de até $9 \stackrel{\circ}{\circ}$ ), quando se utilizou cobertura na superfície do solo, em que, observaram temperaturas superiores a $40^{\circ} \mathrm{C}$ em solo sem cobertura e $31^{\circ} \mathrm{C}$ em solo com cobertura de $4 \mathrm{t} \mathrm{ha}^{-1}$ de palhada de aveia.

O mesmo foi encontrado nas avaliações entre os $20-25 \mathrm{~cm}$ de profundidade, porém com menores variações dos valores entre os tratamentos. No tratamento sem cobertura houve variações de 17,6 a $26,4 \stackrel{\circ}{ } \mathrm{C}$, com média de $24,3 \stackrel{\circ}{\circ} \mathrm{C}$. Com cobertura de $4 \mathrm{t} \mathrm{ha}^{-1}$ os valores oscilaram entre 17,5 e $26,2^{\circ} \mathrm{C}$, com valor médio de $23,8{ }^{\circ} \mathrm{C}$, e com $8 \mathrm{t} \mathrm{ha}^{-1}$ a mínima foi $17,0{ }^{\circ} \mathrm{C}$ e a máxima $26,2{ }^{\circ} \mathrm{C}$, com média de $23,3{ }^{\circ} \mathrm{C}$
(Figura 3B). Avaliando a temperatura e a amplitude térmica do solo, Cademartori et al. (2010) também encontraram menores valores nos solos com cobertura vegetal morta quando comparados com o solo sem cobertura, no cultivo de azevém.

Para a temperatura mínima, na variação foi diferente das demais temperaturas, em que a 5-10 $\mathrm{cm}$ de profundidade (Figura 4A), o menor valor de temperatura mínima encontrado em quase todo o período foi no tratamento com o cultivo de milho em solo sem cobertura, e o maior valor foi com $8 \mathrm{t} \mathrm{ha}^{-1}$ de cobertura de braquiária. Monitorando a temperatura mínima a $5-10 \mathrm{~cm}$ de profundidade no perfil do solo, no solo sem cobertura, os valores oscilaram de 14,2 a $24,9 \stackrel{\circ}{\circ}$, com média de 21,6 ${ }^{\circ} \mathrm{C}$. Com cobertura de $4 \mathrm{t} \mathrm{ha}^{-1}$ de braquiária, os valores variaram de 15,1 a $25,3^{\circ} \mathrm{C}$, com média de $22,2^{\circ} \mathrm{C}$ e com cobertura de $8 \mathrm{t} \mathrm{ha}^{-1}$ os valores variaram de 15,5 a $25,3 \stackrel{\circ}{\circ} \mathrm{C}$ e média de $22,3 \stackrel{\circ}{\circ}$ (Figura $4 \mathrm{~A}$ ).

A temperatura mínima avaliada nas camadas de 20-25 cm do solo sem cobertura oscilou de 16,4 a $25,7^{\circ} \mathrm{C}$, com média $23,1^{\circ} \mathrm{C}$, com $4 \mathrm{tha}^{-1}$ de cobertura os valores variaram de 16,8 a $25,8 \stackrel{\circ}{\circ} \mathrm{C}$, com valor médio de $21,1^{\circ} \mathrm{C}$ e com $8 \mathrm{t} \mathrm{ha}^{-1}$ de cobertura as variações ocorreram entre 16,4 a $25,5^{\circ} \mathrm{C}$, com média de $22,7^{\circ} \mathrm{C}$ (Figura 4B).

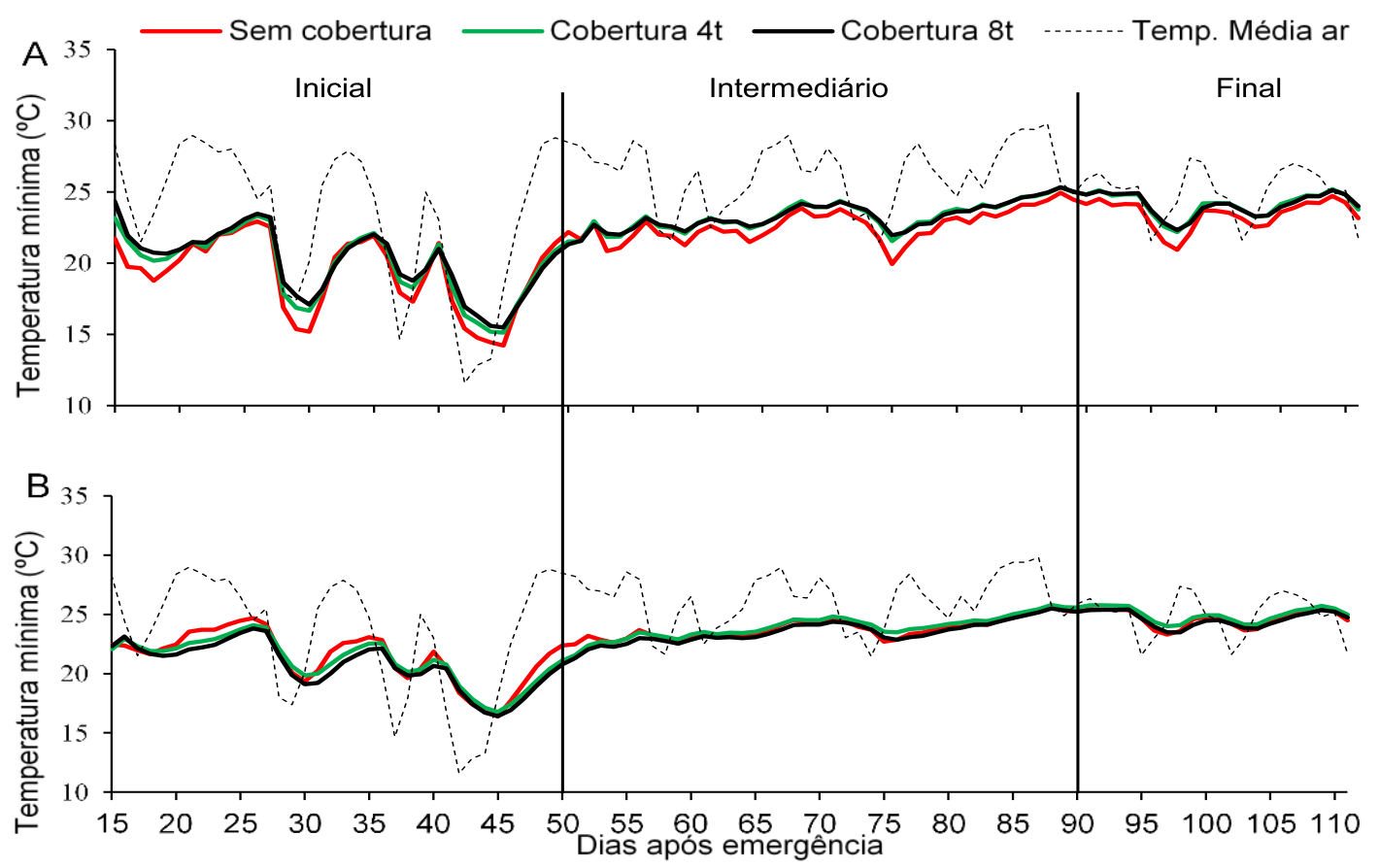

Figura 4 - Temperatura mínima diária do solo nos diferentes tratamentos e nas profundidades de $5-10 \mathrm{~cm}(\mathrm{~A})$ e $20-25 \mathrm{~cm}$ (B), avaliadas durante o período de 09 de agosto a 13 de novembro de 2016, (15 a 110 dias após a emergência da cultura do milho). Tangará da Serra - MT. Daily minimum soil temperature in the different treatments and depths of $5-10 \mathrm{~cm}(A)$ and $20-25 \mathrm{~cm}(B)$, evaluated during the period from August 9 to November 13, 2016, (from 15 to 110 days after emergence of the mazie crop). Tangará da Serra - MT.

Na profundidade de $20-25 \mathrm{~cm}$ as temperaturas mínimas do solo permaneceram praticamente constantes após os $50 \mathrm{DAE}$, sendo o maior valor da mínima $26,4 \stackrel{\circ}{\circ}$ e o menor valor $22,6 \stackrel{\circ}{\circ}$. Dos 15 aos
$50 \mathrm{DAE}$ as variações foram maiores sendo o maior valor da mínima $26,1{ }^{\circ} \mathrm{C}$ e o menor valor $15,8 \stackrel{\circ}{\circ} \mathrm{C}$, devido ao menor sombreamento da superfície do solo pelas plantas de milho, pois estas se 
encontravam na fase inicial apresentando menor cobertura vegetal possibilitando que mais radiação solar atinja a superfície do solo e mais energia seja transmitida desta para as camadas mais profundas.

A amplitude térmica do ar apresentou semeIhança com a do solo (Figura 5), principalmente na camada superficial de $5-10 \mathrm{~cm}$. Porém, os valores da temperatura do ar foram superiores à do solo nas profundidades e nos tratamentos estudados. A menor amplitude da temperatura do ar foi de $4,5 \stackrel{\circ}{ } \mathrm{C}$, chegando a $20,0^{\circ} \mathrm{C}$, o que pode ser explicado devido ao solo estar coberto com palhada. Essa cobertura possibilita menor perda/troca de calor do solo para a atmosfera, resultando em amplitudes menores em relação a da temperatura do ar, que perde ou ganha calor mais facilmente quando comparado com uma superfície coberta (Carneiro et al., 2013; Oliveira et al., 2019).

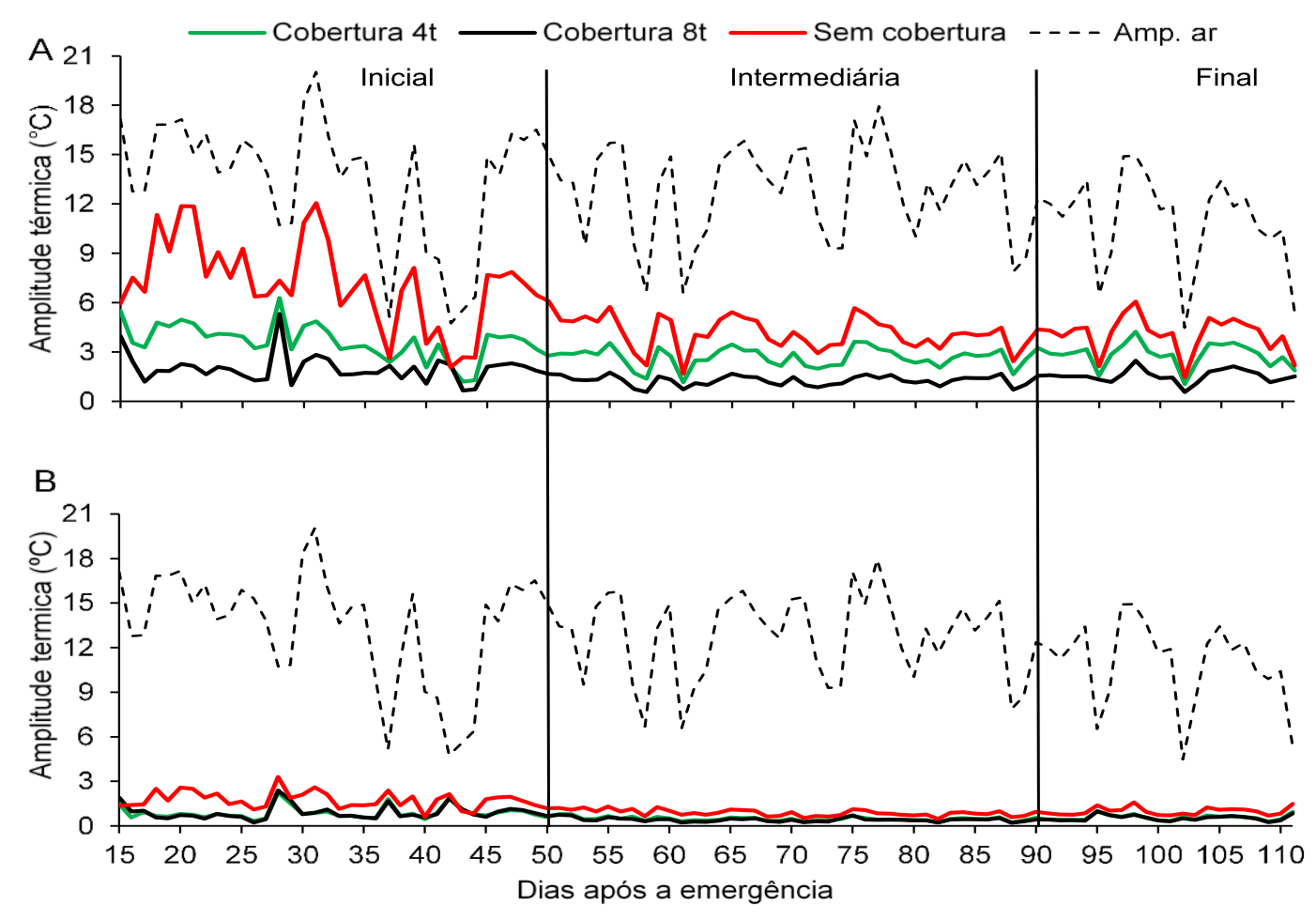

Figura 5 - Amplitude térmica diária do solo e do ar nos diferentes tratamentos e nas profundidades de 5-10 cm (A) e 20-25 cm (B), avaliadas durante o período de 09 de agosto a 13 de novembro de 2016 (15 a 110 dias após a emergência da cultura do milho). Tangará da Serra - MT. Daily soil and air temperature range in the different treatments and depths of $5-10 \mathrm{~cm}(A)$ and $20-25 \mathrm{~cm}(B)$, evaluated during the period from August 9 to November 13, 2016 (from 15 to 110 days after emergence of the maize crop). Tangará da Serra - MT.

A amplitude térmica do solo foi maior no cultivo de milho sem cobertura em ambas as camadas avaliadas. Aos $5-10 \mathrm{~cm}$ a amplitude no solo sem cobertura foi $10,6^{\circ} \mathrm{C}$, no solo com 4 e $8 \mathrm{t} \mathrm{ha}^{-1}$, as amplitudes foram de 5,2 e 4,7 ${ }^{\circ} \mathrm{C}$, respectivamente (Figura 5A). Gasparim et al. (2005) também verificaram redução da amplitude térmica do solo com cobertura, em que a amplitude térmica do solo sem cobertura vegetal foi de $20 \stackrel{\circ}{\circ}$, enquanto para o solo com resíduos de aveia preta o valor foi reduzido para $10{ }^{\circ} \mathrm{C}$. Os solos do tipo argiloso possuem uma condutividade térmica maior, motivo pelo qual apresentam as menores amplitudes térmicas, principalmente em camadas mais profundas (Jong van Lier \& Durigon, 2013; Carneiro et al., 2014).

Nas camadas de $20-25 \mathrm{~cm}$ houve menor amplitude térmica, sendo que o solo sem cobertura apre- sentou os maiores valores de amplitude. Os valores de amplitude térmica do solo foram 2,$9 ; 2,0$ e 2,2 ${ }^{\circ} \mathrm{C}$, para o solo sem cobertura, com cobertura de 4 e de $8 \mathrm{t} \mathrm{ha}^{-1}$, respectivamente (Figura $5 \mathrm{~B}$ ).

Nas duas profundidades avaliadas, bem como nos três tratamentos, nos primeiros 40 dias de avaliação a amplitude apresentou os maiores valores, com redução dos valores ao longo do período, fato relacionado ao crescimento das plantas de milho, que provocaram o sombreamento da superfície do solo e reduziram as oscilações térmicas. Cortez et al. (2015), estudando diferentes sistemas de produção na cultura do milho, observaram que a amplitude térmica do solo até um mês após a emergência foi menor nos tratamentos com escarificação e plantio direto em relação ao convencional; no entanto, após esse período, essas dife- 
renças deixaram de existir, devido à cobertura do solo propiciada pela cultura do milho, em torno de $50 \%$ de cobertura.

A umidade do solo, em função dos tratamentos, apresentou variações e influências da temperatura do solo, da irrigação e precipitação (Figura 6). O comportamento da umidade do solo foi oposto ao da temperatura do solo, ou seja, nos dias em que a temperatura do solo foi baixa, a umidade estava alta e vice-versa.

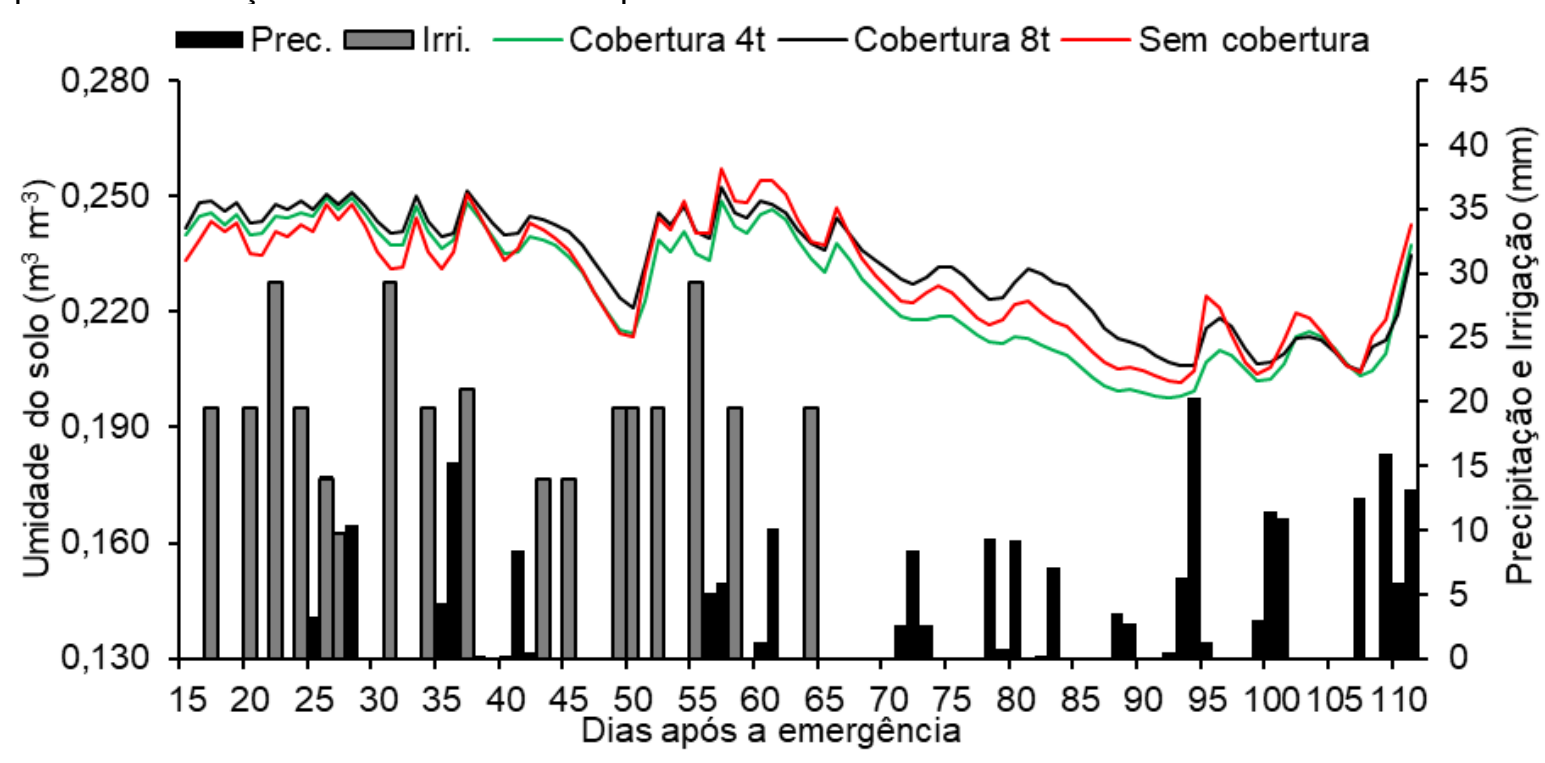

Figura 6 - Umidade do solo $\left(\mathrm{m}^{3} \mathrm{~m}^{-3}\right)$ nos diferentes tratamentos, na profundidade de $30 \mathrm{~cm}$, irrigação e precipitação ocorrida durante o período avaliado de 09 de agosto a 13 de novembro de 2016 (15 a 110 dias após a emergência da cultura do milho). Soil moisture $\left(\mathrm{m}^{3} \mathrm{~m}^{-3}\right)$ in the different treatments, at depth of $30 \mathrm{~cm}$, irrigation and precipitation occurred during the period from August 9 to November 13, 2016 (from 15 to 110 days after emergence of maize).

Solos com maiores porcentagens de argila em sua composição, como no Latossolo presente neste estudo possuem, como característica, elevado número de microporos, os quais têm maior capacidade de reter água em seu interior, apresentando assim maior umidade o que acarreta em aumento na difusividade térmica e assim influenciando na temperatura do solo (Jong van Lier \& Durigon, 2013; Carneiro et al., 2014; Roxy et al., 2014), fator importante que explica como a presença de água no solo interfere na temperatura do mesmo.

Desta maneira, em solos com menores quantidades de água, a difusividade térmica diminui e, assim, a transferência de calor entre ar e solo diminui, ocorrendo diminuição na amplitude térmica da temperatura do solo daquele momento (Roxy et al., 2014; Farias et al., 2018). No período em que ocorrem os maiores índices de umidade, estes propiciaram um resfriamento gradativo do solo ocasionando diferentes valores da temperatura do solo para cada profundidade, ao mesmo tempo, diminuindo o fluxo de energia no solo assim diminuindo a temperatura e ocorrendo menores amplitudes da temperatura do solo (Carneiro et al., 2014).

Pode-se concluir, então, que a ausência de água dificulta o fluxo de calor no solo, dificultando a condução de calor das camadas superficiais para as mais profundas (Funari \& Pereira Filho, 2017; Oliveira et al., 2019). Já a presença de água no solo afeta o fluxo de calor do mesmo, ou seja, a presença de umidade no solo modifica os valores da amplitude da temperatura do solo em função da evaporação (Carneiro et al., 2014; Cortez et al., 2015).

Dos 15 aos 36 dias após à emergência (DAE) da planta, a umidade do solo foi maior no solo com cobertura de $8 \mathrm{t} \mathrm{ha}^{-1}$, seguido pelo tratamento com $4 \mathrm{t} \mathrm{ha}^{-1}$ e o solo sem cobertura. Isso se deve, pelo fato que, a cultura encontrava-se no início da fase de desenvolvimento, até os $36 \mathrm{DAE}$, logo, o índice de área foliar era pequeno. Assim, como a radiação solar atingia mais diretamente a superfície do solo, nos tratamentos com cobertura a palha funcionou como uma camada isolante ao fluxo de calor para o solo o que reduziu o seu aquecimento (Figuras 2, A e B), reduzindo, em consequência, a evaporação. Como a saída de água do solo foi diminuída com a redução da evaporação, a umidade no solo desses tratamentos manteve-se em valores mais elevados em relação ao tratamento sem cobertura.,

Nos períodos de maior umidade do solo, como aos 32 DAE. por exemplo, a amplitude térmica do solo foi diferenciada da dos períodos de menor umidade. Em períodos de maior umidade do solo, foi observado a diminuição dos valores de amplitude térmica do solo. Isso se deve pelo fato de a água agir como regulador térmico, ou seja, a água absorve calor do ambiente, reduzindo a temperatura máxima e aumentando a mínima. Fato semelhante foi encontrado também para a cultura do milho por Cortez et al. (2015).

$O$ fator principal que explica o comportamento da temperatura entre os tratamentos estudados e os 
períodos de maior e menor umidade do solo é o saldo de radiação (energia) que chega ao solo, que é necessária no processo de aquecimento da água e da evaporação (fluxo de calor latente), sobrando pouca energia para o aquecimento do solo, diminuindo a amplitude térmica do mesmo, enquanto nos períodos com menores teores de umidade, a radiação é quase toda consumida pelo fluxo de calor sensível (ar) e pelo fluxo de calor no solo, apresentando maiores temperaturas do solo e, consequentemente maiores amplitudes térmicas (Carneiro et al., 2013; Oliveira et al., 2019). Desta forma, a interação do solo com a água resulta nessa variação da temperatura do solo.

Utilizando palha de cana-de-açúcar, Peres et al. (2010) observaram diminuição da perda de água em solos cobertos com palha, quando comparados com solo sem cobertura. Na camada de 0-20 cm, a perda de água do tratamento sem palha foi de $0,45 \mathrm{~mm} \mathrm{dia}^{-1}$, enquanto no tratamento com palha, a perda foi de $0,21 \mathrm{~mm} \mathrm{dia}^{-1}$, logo, a redução foi de $53,3 \%$ na perda de água em função da cobertura , fato que contribuiu para manter o solo com umidade mais elevada.

A partir de 37 dias após a semeadura a umidade influenciou a temperatura do solo, onde os picos de menores umidade do solo correspondem aos picos de maiores temperaturas do solo (Figura 6).

Até os $60 \mathrm{DAE}$, a umidade do solo encontrava-se entre 0,180 e $0,237 \mathrm{~m}^{3} \mathrm{~m}^{-3}$, isso porque até este período o volume de água irrigado e precipitado foi maior do que nos demais dias, exceto dos 45 aos 51 DAE, em que houve uma diminuição na umidade do solo, mas isso é justificado devido à um pico de alta temperatura do solo que ocorreu em função da alta temperatura do ar, uma vez que a temperatura do solo determina a evaporação e, consequentemente, altera a umidade do solo (Carneiro et al., 2013).

Dos 65 aos 107 DAE a umidade do solo foi reduzida, com valores de $0,101 \mathrm{a} 0,213 \mathrm{~m}^{3} \mathrm{~m}^{-3}$. Durante este período o volume total irrigado e precipitado foi reduzido, fato que contribuiu para a redução da porcentagem de umidade do solo. De acordo com Borges et al. (2014), a umidade no perfil do solo está diretamente relacionada à quantidade de água, seja pela precipitação ou irrigação e, esses resultados comprovaram que a presença da cobertura vegetal (4 e 8 t ha $^{-1}$ de cobertura) em relação ao solo sem cobertura, é de suma importância para favorecer a retenção e, consequentemente, o armazenamento de água no solo.

Dos 15 aos 36 DAE, a umidade no solo sem cobertura foi a menor, porém, depois deste período, no solo sem cobertura ocorreram comportamentos inversos, chegando em alguns momentos a apresentar a maior porcentagem de umidade do solo, como por exemplo aos 57 DAE (Figura 6), nesses casos, houve diminuição da temperatura do solo e elevada umidade no solo descoberto.

No solo com cobertura de $4 \mathrm{t} \mathrm{ha}^{-1}$, na fase ini- cial, até aproximadamente os 35 dias após a emergência, a umidade registrada foi maior do que no solo sem cobertura, no entanto, após os $36 \mathrm{DAE}$, tanto na fase intermediária quanto na final, a umidade foi menor do que a observada no solo sem cobertura.

A cobertura de $8 \mathrm{t} \mathrm{ha}^{-1}$ proporcionou a maior umidade do solo durante quase todo o período estudado, com exceção de alguns dias em que houve picos de altas ou baixas temperaturas, sendo que neste caso, no solo sem cobertura, foi registrado a maior umidade do solo. Isso porque segundo Coelho et al. (2013), o solo descoberto realiza as trocas térmicas entre as camadas do solo de forma mais rápida, o que faz com que este sofra as quedas e os aumentos de temperatura rapidamente $e$, consequentemente, a umidade do solo também é afetada de forma mais rápida.

\section{Conclusões}

A temperatura do solo foi reduzida com o uso da cobertura do solo, principalmente na fase inicial de desenvolvimento da planta de milho. As maiores variações na temperatura do solo ocorreram na profundidade entre $5-10 \mathrm{~cm}$.

O solo coberto com $8 \mathrm{t} \mathrm{ha}^{-1}$ de palhada de braquiária reduziu a temperatura máxima do solo em até $2,9 \stackrel{\circ}{ } \mathrm{C}$. A cobertura do solo proporcionou redução da amplitude térmica do solo de até $5,8 \stackrel{\circ}{ } \mathrm{C}$.

A cobertura de $8 \mathrm{t} \mathrm{ha}^{-1}$ de palhada de braquiária proporcionou a manutenção de maior umidade do solo cultivado com milho.

\section{Agradecimentos}

À Universidade do Estado de Mato Grosso UNEMAT, e a Coordenação de Aperfeiçoamento de Pessoal de Nível Superior (CAPES) pelo apoio financeiro à pesquisa.

\section{Referências}

Albuquerque AW, Santos JR, Moura Filho G, Reis LS (2013) Plantas de cobertura e adubação nitrogenada na produção de milho em sistema de plantio direto. Revista Brasileira de Engenharia Agrícola e Ambiental 17(7):721-726. doi: 10.1590/S141543662013000700005

Allen RG, Pereira LS, Raes D, Smith M (1998) Crop evapotranspiration: Guidelines for computing crop water requirements. Roma: FAO. 328p. (Irrigation and Drainage Paper, 56).

Allen RG, Pereira LS, Raes D, Smith M (2006) Evapotranspiration del cultivo: Guias para la determinación de los requerimientos de agua de los cultivos. Roma: FAO. (Riego y Drenaje Estudio, 56). 
Alvarenga RC, Cabezas WAL, Cruz JC, Santana DP (2001) Plantas de cobertura de solo para sistema plantio direto. Informe Agropecuário 22(208):25-36.

Belan LL, Xavier TMT, Torres H, Toledo JV, Pezzopane JEM (2013) Dinâmica entre temperaturas do ar e do solo sob duas condições de cobertura. Revista Acadêmica Ciências Agrárias e Ambientais 11(1):147154. doi: 10.7213/academica.10.S01.AO17

Borges TKS, Montenegro AAA, Santos TEM, Silva DD, Silva Junior VP (2014) Influência de práticas conservacionistas na umidade do solo e no cultivo do milho (Zea mays L.) em semiárido nordestino. Revista Brasileira de Ciência do Solo 38(6):1862-1873. doi: 10.1590/S0100-06832014000600021

Cademartori RTO, Buriol GA, Righes AA (2010) Influência de diferentes coberturas na temperatura do solo. Disc. Scientia. Série: Ciências Naturais e Tecnológicas 11(1):149-157.

Campbell Scientific Inc, CS (2004) Instruction Manual, CS616 and CS625 Water Content Reflectometers. Logan, UT, USA. 46p.

Carneiro MAC, Cordeiro MAS, Assis PCR, Moraes ES, Pereira HS, Paulino HB, Souza E (2008) Produção de fitomassa de diferentes espécies de cobertura e suas alterações na atividade microbiana de solo de cerrado. Bragantia 67(2):455-462. doi: 10.1590/S000687052008000200021

Carneiro RG, Moura MAL, Silva VPR, Silva Júnior RS, Andrade AMD, Santos AB (2013) Estudo da temperatura do solo em dois biomas florestais nos períodos, chuvoso e seco. Revista Brasileira de Geografia Física 6(4):1009-1022.

Carneiro RG, Moura MAL, Silva VPR, Silva Júnior RS, Andrade AMD, Santos AB (2014) Variabilidade da temperatura do solo em função da liteira em fragmento remanescente de mata atlântica. Revista Brasileira de Engenharia Agrícola e Ambiental 18(1):99-108. doi: 10.1590/S1415-43662014000100013

Coelho MEH, Freitas FCL, Cunha JLXL, Silva KS, Grangeiro LC, Oliveira JB (2013) Coberturas do solo sobre a amplitude térmica e a produtividade de pimentão. Planta Daninha 31(2):369-378. doi: 10.1590/S0100-83582013000200014

Collier LS, Kikuchi FY, Benício LPF, Sousa SA (2011) Consórcio e sucessão de milho e feijão-de-porco como alternativa de cultivo sob plantio direto. Pesquisa Agropecuária Tropical 41(3):306-313.

CONAB - Companhia Nacional de Abastecimento (2020) Acompanhamento de safra brasileira: grãos. v.7 - safra 2019/2020, n.8, oitavo levantamento, maio 2020. Disponível em <https://www.conab.gov.br/infoagro/safras/graos/boletim-da-safra-de-graos>. Acesso em 20 jul. 2020
Cortez JW, Nagahama HJ, Olszevski N, Patrocinio Filho AP, Souza EB (2015) Umidade e temperatura de argissolo amarelo em sistemas de preparo e estádios de desenvolvimento do milho. Engenharia Agrícola 35(4):699-710. doi: 10.1590/1809-4430-

Eng.Agric.v35n4p699-710/2015

Cruz JC, Pereira Filho IA, Alvarenga RC, Gontijo Neto MM, Viana JHM, Oliveira MF, Santana DP (2006) Manejo da Cultura do milho em sistema de plantio direto. Informe agropecuário 27(233):42-53.

Dallacort R, Martins JA, Inoue MH, Freitas PSL, Coletti AJ (2011) Distribuição das chuvas no município de Tangará da Serra, médio norte do Estado de Mato Grosso, Brasil. Acta Scientiarum. Agronomy 33(2):193-200. doi: 10.4025/actasciagron.v33i2.5838

Dallacort R, Martins JA, Inoue MH, Freitas PSL, Krause W (2010) Aptidão agroclimática do pinhão manso na região de Tangará da Serra, MT. Revista Ciência Agronômica 41(3):373-379. doi: 10.1590/S180666902010000300008

Dalmago GA, Bergamaschi $\mathrm{H}$, Comiran $\mathrm{F}$, Bianchi CAM, Bergonci JI, Heckler BMM (2004) Soil temperature in maize crops as function of soil tillage systems. In: ISCO 2004 - International Soil Conservation Organization Conference, 23. Resumos expandidos. Brisbane, $4 p$.

Daniel TAD (2011) Avaliação de níveis de irrigação sobre as componentes de produção e produtividade de cultivares de trigo (Triticum aestivum L.) no município de Tangará da Serra-MT. 2011. 53f. Dissertação (Mestrado em Agricultura Tropical). Cuiabá.

Farias $\mathrm{P}$ dos $\mathrm{S}$ de, Souza $L$ da $S$, Paiva $A$ de $\mathrm{Q}$, Oliveira ÁS de, Souza LD, Ledo CA da S (2018) Hourly, daily, and monthly soil temperature fluctuations in a drought tolerant crop. Revista Brasileira de Ciência do Solo 42(e0170221): Epub 22 jan. 2018 doi: $10.1590 / 18069657$ rbcs20170221

Fenner W, Dallacort R, Freitas PSL de, Faria Júnior C A, Carvalho MAC, Bariviera G (2016) Dual crop coefficient of common bean in Tangará da Serra, Mato Grosso. Revista Brasileira de Engenharia Agrícola e Ambiental 20(5):455-460. doi: 10.1590/18071929/agriambi.v20n5p455-460

Freitas PSL, Dallacort R, Barbieri JD, Bertonha A. Manejo de água. In: Brandão Filho JUT, Freitas PSL, Berian LOS, Goto R (orgs.) (2018) Hortaliças-fruto. Maringá: Eduem. p.163-208.

Funari FL, Pereira Filho AJ (2017) Estimativa do fluxo de calor no solo a partir da temperatura do solo em São Paulo, SP. Revista do Instituto Geológico 38(1):49-57. doi: 10.5935/0100-929X.20170004 
Furlani CEA, Gamero CA, Levien R, Silva RP, Cortez JW (2008) Temperatura do solo em função do preparo do solo e do manejo da cobertura de inverno. Revista Brasileira de Ciência do Solo 32(1):375-380.

Garcia CMDP, Andreotti M, Tarsitano MAA, Teixeira Filho MCM, Lima AEDS, Buzetti S (2012) Análise econômica da produtividade de grãos de milho consorciado com forrageiras dos gêneros Brachiaria e Panicum em sistema plantio direto. Revista Ceres 59(2):157-163. doi: $10.1590 /$ S0034 737X2012000200002

Gasparim E, Ricieri RP, Silva SL, Dallacort R, Gnoatto E (2005) Temperatura no perfil do solo utilizando duas densidades de cobertura e solo nu. Acta Scientiarum. Agronomy 27(1):107-115. doi: 10.4025/actasciagron.v27i1.2127

Jong van Lier Q de, Durigon A (2013) Soil thermal diffusivity estimated from data of soil temperature and single soil component properties. Revista Brasileira de Ciência do Solo 37(1):106-112. doi: 10.1590/S010006832013000100011

Landau EC, Sans LMA, Santana DP (2012) Clima e solo. In: Cruz JC. (ed.). Cultivo do milho. 8.ed. Embrapa Milho e Sorgo, 4 p. Disponível em <http://www.cnpms.embrapa.br/publicacoes/milho_8_e d/climaesolo.htm>. Acesso em 08 out. 2018.

Melo LF (2013) Sensores de temperatura: Termopares. Londrina: UEL. 37p. Disponível em: $<$ http://www.uel.br/pessoal/leonimer/termopares.pdf>. Acesso em 15 dez. 2019.

Murga-Orrillo H, Araújo WF, Abanto-Rodriguez C, Sakazaki RT, Lozano RMB, Polo-Vargas AR (2016) Influência da cobertura morta na evapotranspiração, coeficiente de cultivo e eficiência de uso de água do milho cultivado em cerrado. Irriga 21(20):352-364. doi: 10.15809/irriga.2016v21n2p352-364

Oliveira KAS de, Dallacort R, Barbieri JD, Daniel DF, Tieppo RC, Santos SB dos (2019) Variabilidade mensal e sazonal da temperatura do solo em diferentes condições de cobertura e de profundidades na região de Tangará da Serra, Mato Grosso. Científica 47(3):256-268. doi: 10.15361/19845529.2019v47n3p256-268

Peres JG, Souza CF, Lavorenti NA (2010) Avaliação dos efeitos da cobertura de palha de cana-de-açúcar na umidade e na perda de água do solo. Engenharia Agrícola 30(5):875-886. doi: 10.1590/S010069162010000500010

Roxy MS, Sumithranand VB, Renuka G (2014) Estimation of soil moisture and its effect on soil thermal characteristics at Astronomical Observatory, Thiruvananthapuram, south Kerala. Journal of Earth System Science 123(8): 1793-1807. doi: 10.1007/s12040-0140509-x
Santos HG, Jacomine PKT, Anjos LHC, Oliveira V.A, Lumbreras JF, Coelho MR, Almeida JA, Araujo Filho JC, Oliveira JB, Cunha TJF (2018) Sistema Brasileiro de Classificação de Solos. 5. ed. Brasília: Embrapa Solos. 356p.

Santos TEM, Montenegro AAA, Silva DD (2011) Umidade do solo no semiárido pernambucano usando-se reflectometria no domínio do tempo (TDR). Revista Brasileira de Engenharia Agrícola e Ambiental 15(7):670-679. doi: 10.1590/S141543662011000700004

Silva VR, Reichert JM, Reinert DJ (2006) Variação na temperatura do solo em três sistemas de manejo na cultura do feijão. Revista Brasileira de Ciência do Solo 30(3):391-399. doi: 10.1590/S010006832006000300001

Silva WM (2016) Produtividade do trigo irrigado, emissão $\mathrm{C}-\mathrm{CO}_{2}$, atributos físicos-hídricos em um latossolo de cerrado sob diferentes preparos. 2016. 114f. Tese (Doutorado em Agricultura Tropical). Cuiabá.

Souza KB, Pedrotti A, Resende SC, Santos HMT, Menezes MMG, Santos LAM (2008) Importância de novas espécies de plantas de cobertura de solo para os tabuleiros costeiros. Revista da Fapese 4(2):131-140.

Stefanoski DC, Santos GG, Marchão RL, Petter FA, Pacheco, Leandro P (2013) Uso e manejo do solo e seus impactos sobre a qualidade física. Revista Brasileira de Engenharia Agrícola e Ambiental 17(12):1301-1309. doi: 10.1590/S141543662013001200008

Vasconcelos AT, Tieppo RC, Dallacort R, Santi A, Andrea MC da $S$ (2018) Laboratory temperature compensating calibration procedure for soil water content determination by reflectometry. Científica 46(3), 221-225. doi: 10.15361/1984-5529.2018v46n3p221225.

Veiga M, Reinert DJ, Reichert JM (2010) Tillage systems and nutrient sources affecting soil cover, temperature and moisture in clayey Oxisol under corn. Revista Brasileira de Ciência do Solo 34(6):2011-2020. doi: 10.1590/S0100-06832010000600025

Wazilewski WT, Werner OV, Medeiros M (2011) Influência da temperatura do perfil do solo no desenvolvimento da cultura da soja na região oeste do $\mathrm{Pa}$ raná. Cultivando o Saber 4(3):66-76. 